\title{
Overcoming the Barriers to Successful Completion of GED Programs among Prison and Jail Inmates
}

\author{
John Stuart Batchelder ${ }^{1}$, Austin O'Neill ${ }^{2}$, Ashley Diane Rodriguez ${ }^{3} \&$ Rebecca Tibbs $^{3}$ \\ ${ }^{1}$ A professor of Criminal Justice at the University of North Georgia whose research interests include sentencing, rape, and \\ inmate education, United States \\ ${ }^{2}$ An undergraduate student at the University of North Georgia currently pursuing degrees in Criminal Justice and \\ Chinese Language and Culture, United States \\ ${ }^{3}$ A graduate of the University of North Georgia with a degree in Criminal Justice, United States \\ Correspondence: John Stuart Batchelder, A professor of Criminal Justice at the University of North Georgia whose \\ research interests include sentencing, rape, and inmate education, United States.
}

Received: October 18, 2017

doi:10.11114/ijsss.v6i1.2710
Accepted: November 11, $2017 \quad$ Available online: November 23, 2017

URL: https://doi.org/10.11114/ijsss.v6i1.2710

\begin{abstract}
This study examines the barriers faced by inmates participating in General Educational Development (GED) courses in prisons and jails, with the goal of proposing strategies for the removal of these barriers. By examining the literature surrounding prison and jail GED programs, the factors are categorized as those unique to each inmate (inmate factors), those experienced within the prison environment (environmental factors), and barriers that arise as a result of social conditions (outside factors). By examining various similar examples in the literature, solutions are discussed that have helped prison inmates overcome similar barriers.
\end{abstract}

Keywords: prison, education, inmates, barriers, solutions

\section{Introduction}

Prison and Jail General Educational Development (GED) programs, which are geared to prepare inmates to return to society, face a number of obstacles (Hackman, 1997). This article focuses on improving GED program completion by providing insight into the common factors that are blocking success. The intention is to identify some of those obstacles, and propose solutions based on strategies from recent correctional research. We explore some of these factors in order to help inmates avoid abandoning their efforts to complete the GED diploma while incarcerated.

Since earning a GED certificate is essential for attaining employment after release, and can even contribute to an overall sentence-length reduction (by influencing parole decisions favorably), these programs must keep inmates engaged and focused through completion. Historically, success in that regard has been limited. A study examining the completion rates at the turn of the millennium found that only $22 \%$ of jail inmates, and $33 \%$ of prison inmates, complete GED instruction prior to release (Harlow, 2003). Using research that has responded to the need since that study was conducted, we have identified three categories of barriers that hinder inmates and undermine their efforts to complete GED instruction: personal factors, environmental factors, and outside factors. Found within each category are reasons that contribute to the problem, and we present several corresponding solutions.

\section{Review of the Literature}

Examples exist throughout the education literature where problems have been identified and solutions were proposed based on successful results in GED completion. Those studies that have pertained particular to incarcerated students were used to formulate the basis of our proposal.

\subsection{Category I-- Personal Factors}

The first category, personal factors, contains two reasons for failing to complete that are unique to each inmate: 1) family problems and 2) motivation. Research demonstrates that many inmates can overcome personal problems, and experience improved achievement with increased academic tenacity, when exposed to simple interventions. 


\subsubsection{Family Problems}

The first reason, family problems, functions as a distraction by redirecting an inmate's focus from academics to trying to solve, or at least experiencing anxiety over, the issues their families are facing (Jovanic, 2011). These issues can range from a child's chronic illness to marital problems, in addition to the frequent "distancing"some relatives use to "save face " from the shame of having an incarcerated family member, all which pose a threat to education efforts. However, problems like these can be addressed in part through the provision of parenting programs (Davis, 2001) and family wellness classes (Bell, \& Cornwell, 2015).

Instructing inmates in parenting skills helps them view relationship problems from a less egocentric perspective. Not only are they able to see a person's argument from their own point of view (say a parent, or spouse, or offspring's perspective), but from the perspective of the other as well. This outcome was realized in two programs, one in Indiana for males, and one designed for female inmates used in both Oklahoma and Texas. The learned skills were found to reinforce relationships with family members at home using a curriculum centered on mutual respect, moral development, and ethical considerations. When used in conjunction with an education and life-skills focus, it was found that the effectiveness of the GED instruction was enhanced. Therefore, awareness of parenting skills were shown to benefit inmates not only with family relationships, but also in the furthering of their own education. The emphasis in these two state programs is on assisting with, not only the educational deficiencies of the women, but addressing the ir emotional needs as well. This family connection is well-accommodated in the family wellness classes, where the prisoners in Indiana were shown how to develop successful relationships with those whom they may have hurt (children), and those who have hurt them (abusive parents) (Davis, 2001; Bell, \& Cornwell, 2015).

\subsubsection{Motivation}

The seeds that limit motivation often lie within an institution's correctional philosophy (Palmer, 2012). Owing to the ideological desire to "punish" offenders, an oppressive mindset pervades the correctional environment, and therefore inundates inmates with feelings of bitterness and defeat. These emotions are usually accompanied by higher levels of stress. Motivation to complete or enroll in classes is dampened by the notion that work assignments, which provide inmates with money for necessities, often occur at the same time as instructional opportunities. This subordinates "education" in favor of "addressing economic realities," such as obtaining necessities (Jovanic, 2011; Palmer, 2012).

Progress was achieved in addressing these stressful side-effects at a correctional center in Taft, Oklahoma, where stress-levels were reduced by breaking instruction into short concise lessons (Hall, 2015). This strategy made use of a succinct, shortened period of instruction time (three to four month-modules) that included stand-alone teaching classes with one-on-one tutoring. This technique evidenced increased GED achievement where students had experienced only limited success previously, because inmates reported higher levels of motivation in addition to elevated self-esteem. Likewise, a study in Manchester, Kentucky found that providing inmates with a GED "orientation" program at the outset of instruction proved beneficial in reducing dropouts (Alewine, 2010). The inmates were divided into two groups for the purpose of assessing the intervention. Inmates who participated in the week-long "orientation" group, increased participation and motivation by remaining engaged throughout the instruction to a larger degree than did the control group inmates, who received no intervention.

So examples exist in the literature that seem to bring hopeful solutions to the first category of educational barriers: personal problems. Although more research is necessary in order to draw definitive conclusions on male inmates, the inclusion of parenting classes for inmates with family issues seems to be a worthwhile approach. Additionally, manipulation of class-periods, module-lengths, and the inclusion of intro-orientation sessions, all work to reduce stress and increase motivation, which are therefore certainly worthy of consideration as well. Together these strategies have shown success in ameliorating personal issues that hinder inmates from their academic pursuits.

\subsection{Category II -- Environmental Factors}

The second category centers on factors that are common to most incarceration environments. These factors give rise to three reasons that seem to impact academic success: instructor challenges, lack of supplies and materials, and inmate social factors.

\subsubsection{Instructor Challenges}

Instructors in prisons are impeded by limited funding that affect program-design, student availability for class time, and restrictions on content. Lack of curriculum diversity, as well as waning program availability, crippled efforts at San Quentin to begin inmate learning, because the program had to be originally conceived with only two limited academic offerings (McCarthy, 2006). Certainly the most difficult issue regarding program design is funding, which has fluctuated with prevailing political winds, and has impacted education programs differentially for the past half century (Palmer, 2012).

Toward the end of the period where prisons nationwide engaged in rehabilitation efforts, which was from around 1950 to 
the late 1970's, inmates enjoyed a prolific increase in the availability of education programs. Evidence of that could be seen in 1972, when Pell Grants were extended to include help for incarcerated students with tuition (Lahm, 2009). However, following the ideological shift during the 1980's, which viewed offenders as enemies in the war on crime, by 1993 the Pell Grant programs were cut and all but eliminated. As a result, many of the college programs in prisons across the United States closed. This action stalled educational program-design tailored for the incarcerated population, challenged the design of content for the curriculum, and left instructors without the ability to effectively educate the inmates.

The dynamics at work in society forced lawmakers and politicians to unwittingly defeat the goals of correctional education by arguing that inmates should not be given access to education. This concept, called "principle of least eligibility" by Jeremy Bentham, fueled public apathy in providing inmates with educational programs (Hall, 2015). A solution from the San Quentin model showed program expansion can be achieved by enlisting the help of local community education centers, or community colleges, who may assist with content development and program management without expense to the institution (McCarthy, 2006). That particular effort transformed a program with only two class-offerings at the outset, to one that came to have a total of almost fifteen classes instructed each semester, with three semesters operating each year.

In addition to funding problems, instructors are challenged by student availability to fill seats in prison classrooms. Competition for an inmate's time increases as demands for inmate labor clash with available instruction time (Batchelder \& Pippert, 2001). An example of this would be when prison work hours overlap and conflict with library operating times. Attendance in these prison classrooms is additionally impeded by lockdowns (McCarthy, 2006), involuntary work details (Esperian, 2010, McCarthy, 2006) and prisoner transfers, all which force prisoners to miss class when their long-term productivity interests would probably be better served if the time were spent in education classes (Batchelder \& Koski, 2002). For example, inmates who were engaging in an education program in Las Vegas, Nevada, were "... interrupted to work on road crews, clean-up crews, or at fire camp" (Esperian, 2010, p. 327). That study demonstrated that, in the big picture, cost-savings accrue in the form of reduced recidivism and avoidance of costly "long-term" warehousing, which attests to the necessity for directing the interests of incarc erated students toward their long-term interests.

\subsubsection{Shortage of Supplies and Materials}

Reason two, lack of supplies and materials, include computers, paper, pens, calculators, and limited library materials. This barrier restricts inmates from being able to complete assignments and gain a full understanding of the course work. It should be emphasized that not the least of these shortages of supplies and materials, include availability of online resources. Palmer (2012) found that limitations on resources provided to inmates, such as internet access, impedes student performance and compromises their educational efforts. Widespread budget cuts like these harkened back to the days when legislation restricted, and in some cases forbid, the conduct of prison e ducation. Only recently have these programs rebounded to their pre-1980's level. The actual barrier is, in effect, determined by the institution's funding and the limited distribution of materials (Palmer, 2012).

A solution to this problem was proposed by Larson (2015) at Attica Prison in New York. They achieved reduced educational costs by allowing high school instructors who teach classes that offer dual-credit (high school and college) a course-release at his or her primary institution in exchange for teaching that course in prison. With donated texts from the publisher, there are virtually no costs to the prison for providing what would eventually culminate in an associate's degree for the inmate. Even the paper and personal school supplies are purchased by the inmate him or herself, to demonstrate evidence that the prisoner is a stakeholder in his or her own education (Larson, 2015).

Another solution to the supplies and material shortfall was discovered when funding was proposed in the form of volunteer tutors and solicited donations. It was found that instructor-inspired fundraising activities, such as San Quentin's fund-raising dinner, in addition to generosity of publishers, authors and donors, produced a new source of basic books and supplies. Although it made them reliant on volunteer instructors and donated books, at least the program was viable in the face of these limited resources (McCarthy, 2006). Additionally, the funding issues can be assisted through creative budget management, and educating policy-makers (Esperian, 2010).

\subsubsection{Inmate Social Factors}

Inmate social factors constitute reasons within the category of environmental factors found in various inmate behaviors and interactions within the social environment of the correctional facility. Inmates have revealed in the context of personal interviews that these interactions are typically peppered with innuendo and mind-games. An inmate's participation in the program can often depend on "approval" from inmate leaders, who will use the power of mind control, and bully the actions of others. Prison life contains frequent exchanges where weaker inmates must endure manipulation. These leaders, who would be considered "bullies" in the public school system, manipulate the thoughts and actions of others in order to reinforce the inmate hierarchy, frequently for their own self-gratification. The students are challenged by a failure to 
comply with the "rules" of the GED program while simultaneously conforming to an unwritten code of inmate behavior. The failure is not because of a behavior that an inmate student does, or fails to do, but rather because of disruptive behavior on the part of other persons, who may not even be in the program (Batchelder \& Rachal, 2000).

One solution, albeit controversial, is suggested by Duwe, Hallett, Hays, Jang, \& Johnson, (2015), in the form of a religious intervention. These authors reported that enrollment in a "bible college" program produced particularly impressive results. The study found that the risk for inmate misconduct had decreased by $65 \%$ after the receiving the Christian-oriented bible college program. Another solution to this problem was suggested by both Lahm (2009), and Hackman (1997), who found that inmate areduction in misconduct was accomplished by having the misbehaving inmates actually participate in the prison education programs. This alone gives the inmates something to do and seems to motivate them onto a pattern of better behavior. Although the only statistically significant finding regarding education and reduced rule infractions was found in "college-level" instruction, the trend seemed to suggest that, along with a host of other variables, inmates who received instruction of any kind were more amenable to behavior modification and therefore less likely to engage in misconduct (Lahm, 2009).

\subsection{Category III -- Outside Factors}

The third and final category, outside factors, is a very complex set of issues that affects success in the form of an age-old obstacle: the stigma of being branded with a felony, and serving time in prison. This third category describes the diminished goals and lack of drive brought on by the stigma of conviction. Carver \& Harrison (2016) uncovered evidence that shows, because of the strong relationship between higher education and recidivism, there are pressures on educational programs to solve problems that they are not designed to solve.

The outside factors include connecting what is learned with the perception of what an inmate really needs to function after release (connecting academic content with real-world applicability). This gives rise to an apathetic disposition concerning any program involvement, possibly because there is disillusionment with the institution's effort to rehabilitate. Astigma is attached to anyone who has spent time in prison. Stigmas show themselves in many ways: racism, under-education, socioeconomic status, and the stigma of having a conviction. This multiplicity comprises a barrier to academic success. Stigmas seem to target an inmate's self-confidence, which is key to achievement. There is a paucity of role-models in this environment who might otherwise provide inspiration for self-improvement. The general perception is that a felony record seriously limits potential work supervisor's trust: "You got a felony on your record so nobody wants to trust you or deal with you" (Ray, Grommon, \& Rydberg, 2016, p. 358). This outlook was reinforced by Decker, Ortiz, Spohn, and Hedberg (2015) that examined job interview process of released prisoners whose employment possibilities were negatively impacted by those who had a previous prison record, particularly if they were members of a racial minority.

An examination of their findings gives rise to a possible solution to this barrier. Researchers suggest a methodical strategy for boosting the desirability of released offenders in the eyes of a future employer. This technique is a stepwise approach for acquiring more impressive credentials with each new career move. The first taking advantage of GED certification itself. The second is finding and applying for jobs. Finding a job means access to the internet -- which leads to the interview process. In light of the fact that society has "stigma re-enforcers" (these include the conviction and minority status) at work in the job market, the inmate can fortify his or her image to counteract those re-enforcers (Decker et al., 2015). The counter action involves preparing for rejection, and attaining extra job training and job preparedness, including training in interview skills.

Decker et al. (2015) uncovered evidence that beginning the career-building process with "less visible" post-release jobs (termed "back of the house" jobs, such as a dishwasher), makes it easier to obtain employment than it would be for "visible"jobs (termed 'front of the house' positions, such as a waiter), and therefore should be accepted and encouraged as a means for building a resume for future, higher responsibility positions. To that end, the pre-release prison curriculum can facilitate the utilization of a stepwise process to overcome the inevitable stigma barrier.

\section{Summary and Conclusions}

We have outlined several interventions designed to address retention challenges in prison and jail education programs. By investigating the literature from leading journals in correctional education, we have identified several challenges to learning, and discovered interventions or strategies that show promise.

The addition of parenting programs (Davis, 2001) and family wellness classes (Bell, \& Cornwell, 2015) produced promising findings for inmates who experience challenges in the "personal factors" category (those with family issues). Unmotivated inmates found inspiration when there was a restructure in lesson delivery, as suggested by Hall (2015), and a pre-program "orientation" proved beneficial in reducing dropouts, according to Alewine (2010).

In the "Environmental Factors" category we found instructor challenges (Esperian, 2010) were overcome through more resource allocation (McCarthy, 2006), wherein a supply shortfall was provided for with the help of donated materials and 
volunteer teachers (Larson, 2015). Issues surrounding inmate social factors were resolved with the help of spiritual-life enhancement (Duwe, et, al., 2015), and it was discovered that simple "program-participation" became a means by which inmates experienced fewer conduct problems (Lahm, 2009; Hackman, 1997). And, time-management conflicts gave rise to a solution wherein a reprioritization of inmate activities was found to be beneficial (Esperian, 2010; McCarthy, 2006; Batchelder \& Pippert, 2001)

Carver and Harrison's (2016) research, along with Ray, Grommon, and Rydberg (2016), demonstrated that when goals are misaligned, reducing the stigma associated with prison was the first step in aligning those goals. This problem was amplified upon by Decker, Ortiz, Spohn, and Hedberg (2015), whose findings suggested a remedy with a methodical and stepwise procedure by which each individual could fortify his or her resume and job history, and thereby elevate self-esteem.

So, together each suggested intervention and strategy has shown a degree of success in tackling a complex and multifaceted issue: completing an educational goal while incarcerated. Our suggestions are experimental and inconclusive, however, with the aim of ultimately discontinuing the cycle of recidivis $m$, the successes that have been experienced in the recent literature may prove beneficial in the continuation of the process to assist inmates with their GED completion.

\section{References}

Alewine, H. S. (2010). Andragogical Methods and Readiness for the Correctional Ged Classroom. Journal of Correctional Education, 61(1), 9-22.

Batchelder, J. S., \& Koski, D. D. (2002). Barriers to Inmate Education: Factors that affect the Learning Dynamics of a Prison Education Program. Corrections Compendium, 27(2), 1-5, 16-18.

Batchelder, J. S., \& Pippert, J. M. (2001). Hard Time or Idle Time: Factors Affecting Inmate Choices Between Participation in Prison work and Education Programs. Prison Journal, 82(2), 269-280. https://doi.org/10.1177/003288550208200206

Batchelder, J. S., \& Rachal, J. R. (2000). Effects of A Computer-Assisted-Instruction Program in a Prison Setting: An Experimental Study. Journal of Correctional Education, 51(4), 324-332.

Bell, L. G., \& Cornwell, C. S. (2015). Evaluation of a Family Wellness Course for Persons in Prison. Journal of Correctional Education, 66(1), 45-57.

Carver, L. J., \& Harrison, L. M. (2016). Democracy and the Challenges of Correctional Education. Journal of Correctional Education, 67(1), 2-16.

Davis, H. C. (2001). Educating the Incarcerated Female: An Holistic Approach. Journal of Correctional Education, 52(2), 79-83.

Decker, S. H., Ortiz, N., Spohn, C., \& Hedberg, E. (2015). Criminal stigma, race, and ethnicity: The consequences of imprisonment for employment. Journal of Criminal Justice, 43(2), 108-121. https://doi.org/10.1016/j.jcrimjus.2015.02.002

Duwe, G., Hallett, M., Hays, J., Jang, S. J., \& Johnson, B. R. (2015). Bible College Participation and Prison Misconduct: A Preliminary Analysis. Journal of Offender Rehabilitation, 54(5), 371-390. https://doi.org/10.1080/10509674.2015.1043481

Esperian, J. H. (2010). The Effect of Prison Education Programs on Recidivism. Journal of Correctional Education, 61(4), 316-334.

Hackman, K. M. (1997). Correctional Education--Challenges and Changes. Journal of Correctional Education, 48(2), 74-77.

Hall, L. L. (2015). Correctional Education and Recidivism: Toward a Tool for Reduction. Journal of Correctional Education, 66(2), 4-29.

Harlow, C. W. (2003). Education and correctional populations. US Department of Justice, Office of Justice Programs, Bureau of Justice Statistics Washington, DC.

Jovanić, G. (2011). The role of education in the treatment of offenders. Support for Learning, 26(2), 79-82. https://doi.org/10.1111/j.1467-9604.2011.01481.x

Lahm, K. F. (2009). Educational Participation and Inmate Misconduct. Journal of Offender Rehabilitation, 48(1), 37-52. https://doi.org/10.1080/10509670802572235

Larson, D. (2015). Localizing Prison Higher Education. New Directions for Community Colleges, 2015(170), 9-17. https://doi.org/10.1002/cc.20139 
McCarthy, H. J. (2006). Educating Felons: Reflections on Higher Education in Prison. Radical History Review, 96, 87-94. https://doi.org/10.1215/01636545-2006-005

Palmer, S. M. (2012). Postsecondary Correctional Education. Adult Learning, 23(4), 163-169. https://doi.org/10.1177/1045159512457918

Ray, B., Grommon, E., \& Rydberg, J. (2016). Anticipated Stigma and Defensive Indi vidualism During Postincarceration Job Searching*. Sociological Inquiry, 86(3), 348-371. https://doi.org/10.1111/soin.12124

\section{Copyrights}

Copyright for this article is retained by the author(s), with first publication rights granted to the journal.

This is an open-access article distributed under the terms and conditions of the Creative Commons Attribution license which permits unrestricted use, distribution, and reproduction in any medium, provided the original work is properly cited. 